\title{
ПАЛЛАДИЕВЫЙ КОМПЛЕКС КАМФОРАЗАМЕЩЕННОГО ТЕТРАПИРАЗИНОПОРФИРАЗИНА КАК СТАЦИОНАРНАЯ ФАЗА ДЛЯ ГАЗОВОЙ ХРОМАТОГРАФИИ
}

\author{
Г.В. Кувшинов, А. В. Суровегин, М. О. Баканов, А.В. Маслов \\ ГРИГОРИЙ ВЛАДИМИРОВИЧ КУВШИНОВ - к.х.н., научный сотрудник научно-исследовательского от- \\ деления учебно-научного комплекса «Пожаротушение». Область научных интересов: газовая хромато- \\ графия; жидкие кристалль, макрогетерочиклические соединения, их свойства и применение.
}

\begin{abstract}
АНТОН ВЯЧЕСЛАВОВИЧ СУРОВЕГИН - начальник научно-исследовательского отделения учебно-научного комплекса «Пожаротушение», капитан внутренней службы. Область научных интересов: разработка и совершенствование средств, способов и методов подготовки специилистов в области обеспечения пожарной безопасности, тушения пожаров и проведения аварийно-спасательньх работ.
\end{abstract}

МАКСИМ ОЛЕГОВИЧ БАКАНОВ - к.т.н., дочент, начальник кафедры пожарной тактики и основ аварийно-спасательных и других неотложных работ (в составе учебно-научного комплекса «Пожаротушение»), майор внутренней службы. Область научных интересов: синтез систем управления в подразделениях пожарной охраны.

АЛЕКСЕЙ ВЛАДИМИРОВИЧ МАСЛОВ - начальник учебно-научного комплекса «Пожаротушение», полковник внутренней службы. Область научных интересов: совершенствование системы управления пожарно-спасательными подразделениями.

153040, Российская Федерация, г. Иваново, пр-т Строителей, д. 33, Федеральное государственное бюджетное образовательное учреждение высшего образования «Ивановская пожарно-спасательная академия Государственной противопожарной службь Министерства Российской Федерации по делам гражданской обороны, чрезвычайным ситуациям и ликвидации последствий стихийных бедствий».

Проведена модификация поверхности диатомитового адсорбента Хезасорб AW-HMDS тетра (1 ',7',7'триметилбичикло[2.2.1]гептано[2',3'-b]-пиразинопорфиразином Pd(II). Методом газовой хроматографии изучена адсорбция паров ряда органических соединений на поверхности модифищированных адсорбентов. В качестве сорбатов выбраны электронодонорные изомеры метилпиридина и диметилпиридина, изомеры неполярных ксилолов, спиртов и другие углеводороды, способные к проявлению различного типа межмолекулярных взаимодействий с металлопиразинопорфиразином. Рассчитаны удельные удерживаемые объемы сорбатов, высоты, эквивалентные теоретическим тарелкам, число теоретических тарелок для характеристики хроматограмм. Обсуждается влияние температуры и химической природы сорбатов на термодинамические характеристики сорбиии. Рассчитаны факторы разделения близкокипящих ароматических и гетероароматических соединений. Экспериментально установлено, что адсорбент, модифииированный тетра $(1,7$ ',7'-триметилбицикло[2.2.1]гептано[2',3'-b]пиразинопорфиразином Рd(II), проявляет высокую селективность по отношению к близкокипящим соединениям различной природы и хорошую эффективность при их разделении.

Ключевые слова: газовая хроматография, адсорбент, удельный удерживаемый объем, сорбат, сорбция, металлопиразинопорфиразин. 


\title{
PALLADIUM COMPLEX OF CAMPHORO SUBSTITUTED TETRAPIRAZINOPORPHORIZINE AS STATIONARY PHASE FOR GAS CHROMATOGRAPHY
}

\author{
G. V. Kuvshinov, A. V. Surovegin, M. O. Bakanov, A. V. Maslov \\ 33, Stroitelej Avenue, Ivanovo, 153040, Russia. Federal State Budget Educational Establishment of Higher \\ Education «Ivanovo Fire Rescue Academy of State Firefighting Service of Ministry of Russian Federation for Civil \\ Defense, Emergencies and Elimination of Consequences of Natural Disasters».
}

The surface of the diatomite adsorbent Hezasorb AW-HMDS tetra (1 ', 7', 7'-trimethylbicyclo [2.2.1] heptano [2 ' 3'-b] pyrazinoporphyrazine Pd (II) was modified by gas chromatography. organic compounds on the surface of modified adsorbents. The electron-donating isomers of methylpyridine and dimethylpyridine, isomers of nonpolar xylenes, alcohols and other hydrocarbons capable of manifesting various types of intermolecular interactions with metallophthalocyanine were selected as sorbates. The effective retention volumes of sorbates, the heights equivalent to theoretical plates, the number of theoretical plates for characterizing chromatograms, discusses the influence of temperature and chemical nature of the sorbates on the thermodynamic characteristics of sorption, and the separation factors of boiling aromatic and heteroaromatic compounds are calculated. 7', 7'-trimethylbicyclo [2.2.1] heptano [2', 3'-b] pyrazinoporphyrazine Pd (II), shows high selectivity with respect to close boiling compounds of various nature and good efficiency in their separation.

Key words: gas chromatography, adsorbent, specific retention volume, sorbate, sorption, metallophthalocyanine.

\section{Введение}

Среди аналитических методов анализа газовая хроматография занимает особое место. Газовая хроматография - высокоточный, высокотехнологичный, эффективный метод анализа, позволяющий с легкостью анализировать биологические [1-3] и нефтехимические [1] объекты, пищевую продукцию $[4,5]$ или сигаретный дым [6]. Эффективное разделение компонентов анализируемой смеси методом газовой хроматографии во многом обеспечивается сорбционными свойствами адсорбента, находящегося в колонках. В настоящее время в распоряжении исследователей имеется достаточно широкий выбор адсорбентов для газовой хроматографии [7-11]. Одними из наиболее распространенных адсорбентов являются различные марки диатомитов, представляющие собой кальцинированную химически модифицированную глину с щелочными добавками. Однако на поверхности таких диатомитов присутствует повышенная нежелательная поверхностная активность, которая может приводить к ухудшению газохроматографического эксперимента. Как правило, для устранения нежелательной поверхностной активности, проводят модификацию адсорбента. Так, промывка кислотой или щелочью, а также обработка силанизирующими реагентами существенно улучшают свойства поверхности Хро- матона [12]. Однако, наиболее перспективным является адсорбционное модифицирование поверхности адсорбента. Такой подход позволяет регулировать вклады энергии неспецифических и специфических межмолекулярных взаимодействий адсорбат - адсорбент за счет экранирования наиболее неоднородных мест поверхности диатомита. Таким примером могут служить жидкокристаллические соединения [13-20]. Нам удалось экспериментально доказать, что супрамолекулярный фактор и формирование цепочечных наноструктур позволяют достичь высокой селективности при газохроматографическом разделении структурных изомеров ксилола, метиланизола, диметилпиридина, крезола. Появляется возможность эффективно анализировать и более высококипящие вещества.

В последние годы интерес к макрогетероциклическим соединениям в газовой хроматографии обусловлен их способностью к комплексообразованию, высокой химической и термической стабильностью, а хорошо известные оптические и эмиссионные свойства макрогетероциклов позволяют использовать их для научных и высокотехнологичных практических целей [21, 22]. Так, металлофталоцианины ранее были исследованы в качестве модификаторов углеродных адсорбентов [23, 24], однако они не проявили хороших хроматографических свойств. Кроме этого фталоцианин и его 
металлокомплексы не растворимы в органических растворителях, что затрудняет проведение модификации. Нами была предложена модификация поверхности Хроматона и Хезасорба камфоразмещенным тетрапиразинопорфиразином [25] и его медным [26] и никелевым [27] комплексами. Модифицированные адсорбенты показали отличные селективные и аналитические свойства, однако, некоторые из них обладали низкой селективностью по отдельным парам сорбатов либо обладали низкой эффективностью и производительностью, что затрудняло идентификацию хроматограмм.

Исходя из этого цель работы заключалась получении результатов исследования методом газовой хроматографии сорбционных и селективных свойств сорбента на основе тетра(1',7',7'триметилбицикло[2.2.1]гептано[2',3'-b]пиразинопорфиразина $\operatorname{Pd}(\mathrm{II})$.

\section{Экспериментальная часть}

В работе использовали диатомитовый адсорбент Хезасорб AW-HMDS («Chemapol», PrahaCzechoslovakia). Хезасорб AW-HMDS-кальцинированная химически очищенная диатомитовая глина (90-95\% $\% \mathrm{SiO}_{2} ; 3,5 \% \mathrm{Al}_{2} \mathrm{O}_{3} ; 1,5 \% \mathrm{Fe}_{2} \mathrm{O}_{3} ; 0,09 \% \mathrm{TiO}_{2}$; 0,5\% $\left.\mathrm{CaO}+\mathrm{MgO} ; 0,5-1,0 \% \mathrm{Na}_{2} \mathrm{O}+\mathrm{K}_{2} \mathrm{O}\right)$, удельная

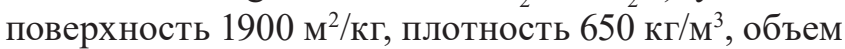
пор 600-700 см $3 /$ кг, средний диаметр пор 120 нм. Тетра(1',7',7'-триметилбицикло[2.2.1]гептано-[2',3'b]-пиразино)-порфиразин $\mathrm{Pd}$ ((Cam) $\mathbf{P z}-\mathbf{P d})$ (рис. 1) синтезировали по известной методике [28].

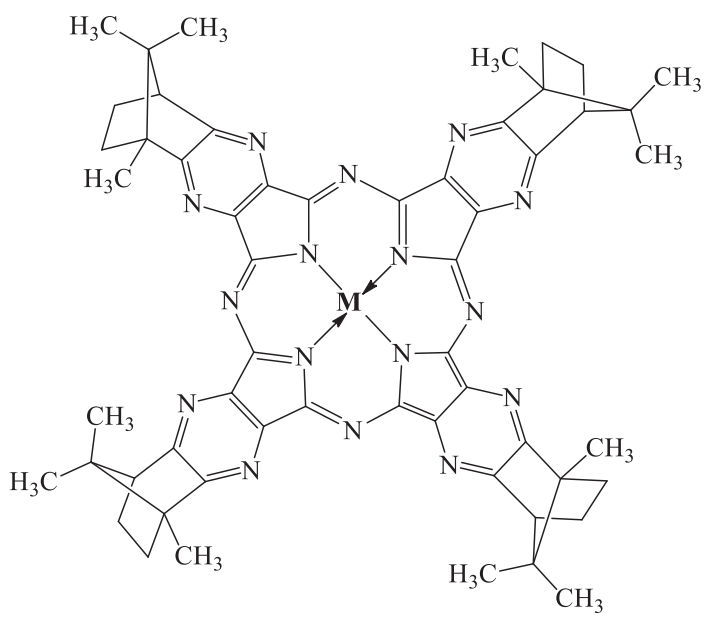

где $\mathrm{M}=\mathrm{Pd}$.

Рис. 1. Структурная формула тетра(1',7',7'-триметилбицикло[2.2.1]гептано[2',3'-b] пиразино-порфиразина Pd(II)

В качестве сорбатов использовали 17 органических соединений - диметилпиридины (лутиди- ны), метилпиридины (пиколины), пиридин, диметилформамид, ксилолы, бензол, циклогексан, этанол, пропанол-1, пропанол-2, бутанол-1, бутанол-2. Все вещества были марки «ОСЧ» компании Aldrich. Для приготовления модифицированного сорбента использовали хлороформ марки «ОСЧ» от компании Aldrich.

\section{Annapamypa}

Исследования методом дифференциально-сканирующей калориметрии (ДСК) были выполнены на приборе NETZSCH DSC 204 F1. Измерения проводили при нагревании и охлаждении в динамическом режиме в токе аргона со скоростью $10^{\circ} \mathrm{C} / \mathrm{Mин}$ в интервале температур от $25^{\circ} \mathrm{C}$ до $250{ }^{\circ} \mathrm{C}$. Навеска 5-10 мг.

Термогравиметрический анализ (ТГА) проводили на приборе NETZSCH STA A-0177-M в динамическом режиме в алюминиевых тиглях в токе аргона. Скорость подъема температуры составляла $10{ }^{\circ} \mathrm{C} /$ мин, интервал температур от $25^{\circ} \mathrm{C}$ до $750{ }^{\circ} \mathrm{C}$, навеска 2-5 мг. Математическую обработку экспериментальных данных проводили с использованием компьютерной программы NETZSCH Proteus Analysis.

Газохроматографический эксперимент проводили на газовом хроматографе Shimadzu GC-2014 c высокочувствительным пламенно-ионизационным детектором, обеспечивающим регистрацию ионизационного тока в интервале температур от $0{ }^{\circ} \mathrm{C}$ до $400{ }^{\circ} \mathrm{C}$. Хроматограф снабжен программным обеспечением Shimadzu GCsolution Chromatography Data System Version 2.4. При помощи данного программного обеспечения в ходе эксперимента устанавливается и поддерживается с точностью $\pm 0,1{ }^{\circ} \mathrm{C}$ температура колонки, испарителя $\left(200{ }^{\circ} \mathrm{C}\right)$ и детектора $\left(200{ }^{\circ} \mathrm{C}\right)$, расход газа-носителя гелия (30-60 мл/мин) с точностью 0,1 мл/мин и давление газа-носителя на входе и выходе из колонки с точностью 0,1 кПа, производится регистрация времени удерживания тестовых сорбатов в хроматографической колонке с точностью 0,1 с, а также расчет площади пика, высоты пика, отношения площади пика к его высоте и числа теоретических тарелок. Ввод проб (не более 0,1 мкл) в хроматографическую колонку осуществляли с помощью системы автоматического закола проб Shimadzu AOC-20i шприцем Shimadzu объемом 10 мкл. «Мертвое время» удерживания, определенное по пропану, составляет 10 с.

\section{Приготовление адсорбента и колонки}

Для приготовления модифицированного адсорбента (Cam) $\mathbf{4} \mathbf{P z}-\mathbf{P d}$ растворяли в хлороформе, 
добавляли к адсорбентам и оставляли на 30 мин. После этого смесь нагревали на водяной бане при перемешивании до полного испарения растворителя. Для удаления следов хлороформа готовые сорбенты сушили 24 ч в вакуумном шкафу при $40{ }^{\circ} \mathrm{C}$ и остаточном давлении 2 мм рт. ст. Стальные насадочные колонки длиной 1 м и внутренним диаметром 3 мм, предварительно промытые ацетоном, при помощи водоструйного насоса и механического вибратора заполняли приготовленными сорбентами и кондиционировали в токе гелия в течение 4 ч при температуре $180{ }^{\circ} \mathrm{C}$. Coдержание модификатора составляло $10 \%$ от массы адсорбента. Удельные удерживаемых объемы сорбатов и параметры разделения вычисляли по известным уравнениям [29]. Характеристика колонки приведена в таблице 1 .

Таблииа 1

\section{Характеристики колонки}

\begin{tabular}{lc}
\hline \multicolumn{1}{c}{ Характеристика } & Значение \\
\hline Материал колонки & Сталь \\
Тип колонки & насадочная \\
Длина колонки, L & 1 м \\
Внутренний диаметр колонки & 3 мм \\
Масса адсорбента в колонке & 3,680 г \\
Масса (Cam) ${ }_{4}$ Рz-Pd в колонке & 0,368 г \\
Степень пропитки & $10 \%$ \\
Мертвое время, $\tau_{\text {м }}$ & 10 с \\
Температура инжектора & $200{ }^{\circ} \mathrm{C}$ \\
Температура детектора & $200{ }^{\circ} \mathrm{C}$ \\
Расход гелия & 60 мл/мин \\
\hline
\end{tabular}

\section{Результаты и их обсуждения}

Проведение газохроматографического эксперимента обычно сопровождается повышенными температурами колонки. Поэтому первым этапом является определение термической стабильности используемого адсорбента в колонке. По данным СТА камфоразамещенный тетрапиразинопорфиразин (Cam) ${ }_{4} \mathbf{P z}-\mathbf{P d}$ является неплавким и термически устойчивым, в диапазоне температур от $70{ }^{\circ} \mathrm{C}$ до $200{ }^{\circ} \mathrm{C}$ не зафиксировано никаких фазовых переходов. Температура начала разложения $\mathrm{Pd}$ комплекса, которая была определена по кривой ТГ как температура потери $1 \%$ массы, составляет $290{ }^{\circ} \mathrm{C}$. При температуре $345{ }^{\circ} \mathrm{C}$ образец теряет $70 \%$ массы. Кроме этого методом СТА проведено исследование процесса испарения (Cam) ${ }_{4} \mathbf{P z}-\mathbf{P d}$ с поверхности адсорбента. При нагревании образ- ца до $250{ }^{\circ} \mathrm{C}$ зафиксировано постоянство массы навески, что свидетельствует о низкой летучести металлоорганического комплекса.

Методом газовой хроматографии изучена сорбция органических соединений, относящихся к разным классам и способных к проявлению различных типов межмолекулярных взаимодействий, адсорбентом «Хезасорб-AW-HMDS - (Cam) ${ }_{4} \mathbf{P z}$ Pd». На основании экспериментальных данных рассчитаны удельные удерживаемые объемы летучих сорбатов (таблица 2).

Таблица 2

Удельные удерживаемые объемы (Vg, $\mathrm{cm}^{3} /$ г) сорбатов сорбентом на основе (Cam) $)_{4} \mathrm{Pz}-\mathrm{Pd}$ при температуре колонки $140^{\circ} \mathrm{C}$

$$
\text { Сорбаты }\left(\mathbf{t}_{\text {кип }},{ }^{\circ} \mathbf{C}\right)
$$

3,4-лутидин $(179,1) \quad 30,40$

3,5-лутидин $(172,2) \quad 20,15$

2,3-лутидин $(161,2) \quad 10,47$

2,4-лутидин $(158,4) \quad 9,77$

2,5-лутидин $(157,0) \quad 9,22$

2,6-лутидин $(144,0) \quad 4,72$

3 -пиколин $(144,0) \quad 7,66$

4-пиколин $(145,4)$

$n$-ксилол $(138,3) \quad 4,21$

м-ксилол $(139,1) \quad 4,19$

бензол $(80,1) \quad 1,03$

ц-гексан $(81,7) \quad 0,40$

бутанол $(117,9) \quad 2,68$

изобутанол $(108,4) \quad 2,21$

пропанол $(97,2) \quad 1,78$

изопропанол $(82,3) \quad 1,31$

этанол $(78,5) \quad 1,36$

Стоит отметить довольно широкий интервал распределения удельных удерживаемых объемов. Это может происходить вследствие неоднородности поверхности адсорбента, а также из-за различий в способе взаимодействия сорбатов с поверхность адсорбента и (Cam) ${ }_{4} \mathbf{P z}-\mathbf{P d}$. Межмолекулярные взаимодействия могут быть слабыми, например, между (Cam) ${ }_{4} \mathbf{P z}-\mathbf{P d}$ и неполярными ксилолами и сильными, например, (Cam) $)_{4} \mathbf{P z}-\mathbf{P d}$ - производные пиридина. Однако во всех случаях химическая индивидуальность сорбатов сохраняется, то есть взаимодействия имеют молекулярный, а не химический характер. Кроме этого сорбаты способны взаимодействовать с поверхностью модифицирован- 
ного адсорбента специфически, поскольку содержат функциональные группы со свободными электронными парами или $\pi$-связями. На поверхности неспецифического адсорбента они способны образовывать ассоциаты, устойчивость которых различна и определяется силой межмолекулярных взаимодействий в системе адсорбент - адсорбат.

Согласно полученным данным из таблицы 2 видно, что наблюдается общая тенденция к увеличению сорбционной емкости с увеличением собственной температуры кипения сорбатов.

Среди изомеров лутидина наиболее сильное удерживание имеет 3,4-лутидин, наименьшее 2,6-лутидин. В данном случае большую роль играет расположение метильных заместителей у сорбатов. Поэтому минимальное значение удельного удерживаемого объема у 2,6-лутидина обусловлено сильным экранированием атома азота, который способен на образование комплексов.

У 3,4-лутидина, напротив, метильные заместители максимально удалены от атома азота, что благоприятно влияет на величину удерживания. Очень слабое удерживание наблюдается у ци- клогексана по сравнению с бензолом. Циклогексан имеет пространственные конформации, которые отрицательно сказываются на удерживании. В то время как, молекула бензола плоская. Это говорит о высокой чувствительности $(\mathbf{C a m})_{4} \mathbf{P z}-\mathbf{P d}$ к пространственному строению сорбатов и к расстоянию. Следует отметить, что межмолекулярные силы быстро убывают с расстоянием, причем среди сил притяжения дисперсионные взаимодействия убывают особенно быстро.

В качестве критериев разделения выступают число теоретических тарелок $\mathrm{N}$ и высота эквивалентная теоретической тарелке Н. (таблица 3)

Сорбент Хезасорб-AW-HMDS - (Cam) ${ }_{4} \mathbf{P z}-\mathbf{P d}$ имеет высокие значения числа теоретических тарелок, и, как следствие, низкое значение высоты эквивалентной теоретической тарелке. Это показывает его высокую эффективность и производительность. Также в сравнении сорбента ХезасорбAW-HMDS - (Cam) ${ }_{4}$ Pz-Pd и Хроматон N-AW (Cam) ${ }_{4} \mathbf{P z}-\mathbf{C u}$ [26] видно огромное преимущество Хезасорба-AW-HMDS - (Cam) ${ }_{4} \mathbf{P z}-\mathbf{P d}$ по показателям N и Н. В сравнении с Хезасорбом AW-HMDS -

Таблица 3

Сравнение числа теоретических тарелок $\mathrm{N}$ и высоты теоретической тарелки $\mathrm{H}$ при $140{ }^{\circ} \mathrm{C}$ на адсорбенте Хезасорб-AW-HMDS - (Cam) ${ }_{4}$ Pz-Pd, Хроматон N-AW - (Cam) $)_{4} \mathrm{Pz}-\mathrm{Cu}$ и Хезасорб AW-HMDS - (Cam) ${ }_{4} \mathrm{Pz}-\mathrm{Cu}[26]$

\begin{tabular}{|c|c|c|c|c|c|c|}
\hline \multirow[t]{2}{*}{ Сорбаты } & \multicolumn{2}{|c|}{$\begin{array}{c}\text { Хезасорб-AW-HMDS - } \\
\text { (Cam) }{ }_{4} \text { Pz-Pd }\end{array}$} & \multicolumn{2}{|c|}{$\begin{array}{l}\text { Хроматон N-AW - } \\
\text { (Cam) })_{4} \mathrm{Pz}-\mathrm{Cu}\end{array}$} & \multicolumn{2}{|c|}{$\begin{array}{l}\text { Хезасорб AW-HMDS - } \\
\text { (Cam) }{ }_{4} \text { Pz-Cu }\end{array}$} \\
\hline & H, мм & $\mathbf{N}$ & Н, мм & $\mathbf{N}$ & Н, мм & $\mathbf{N}$ \\
\hline 3,4-лутидин $(179,1)$ & 161,08 & 9,8 & 180,2 & 5,9 & 7,1 & 140,9 \\
\hline 3,5-лутидин $(172,2)$ & 109,32 & 14,0 & 284,1 & 3,5 & 5,1 & 198,1 \\
\hline 2,3-лутидин $(161,2)$ & 23,65 & 125,2 & 270,3 & 3,7 & 4,7 & 215,4 \\
\hline 2,4-лутидин $(158,4)$ & 32,69 & 70,2 & 278,9 & 3,6 & 5,3 & 189,3 \\
\hline 2,5-лутидин $(157,0)$ & 23,86 & 100,5 & 359,1 & 2,8 & 3,3 & 306,1 \\
\hline 2,6-лутидин $(144,0)$ & 6,62 & 283,7 & 224,7 & 4,5 & 2,9 & 341,7 \\
\hline 3-пиколин $(144,0)$ & 18,86 & 145,7 & 341,7 & 2,3 & 5,9 & 168,5 \\
\hline 4-пиколин $(145,4)$ & 22,88 & 125,9 & 326,0 & 3,1 & 7,6 & 131,0 \\
\hline$n$-ксилол $(138,3)$ & 6,43 & 610,6 & 225,4 & 4,4 & 2,3 & 434,1 \\
\hline м-ксилол $(139,1)$ & 6,50 & 598,9 & 211,0 & 4,7 & 1,9 & 522,7 \\
\hline бензол $(80,1)$ & 3,58 & 136,6 & 37,5 & 26,7 & 2,0 & 493,5 \\
\hline ц-гексан $(81,7)$ & 3,37 & 92,7 & 81,7 & 22,6 & 2,2 & 446,7 \\
\hline бутанол $(117,9)$ & 5,41 & 438,5 & 72,5 & 13,8 & 2,0 & 499,5 \\
\hline изобутанол $(108,4)$ & 4,78 & 401,7 & 14,2 & 70,3 & 2,1 & 485,3 \\
\hline пропанол $(97,2)$ & 4,99 & 309,7 & 40,2 & 24,9 & 2,3 & 438,0 \\
\hline изопропанол $(82,3)$ & 4,24 & 267,6 & 12,2 & 81,8 & 2,4 & 414,6 \\
\hline этанол $(78,5)$ & 7,46 & 168,1 & 20,5 & 48,9 & 5,9 & 170,2 \\
\hline
\end{tabular}


(Cam) ${ }_{4} \mathbf{P z}-\mathbf{C u}$ результаты по производительности схожи [26].

Аналитические возможности (Cam) ${ }_{4} \mathbf{P z}-\mathbf{P d}$ проиллюстрированы на примерах разделения как структурных изомеров, так и сорбатов, имеющих близкие температуры кипения, но относящихся к разным классам. В качестве критерия оценки хроматографического разделения использовали фактор разделения $\alpha$. Фактор разделения $\alpha$ определяется природой сорбента и сорбата, температурой и характеризует качество разделения в зависимости от различия адсорбируемости разделяемых веществ.

Значения $\alpha$ для пар близкокипящих органических соединений представлены в таблице 4 , а хроматограммы модельных смесей представлены на рисунках 2 и 3.

Таблицча 4

Факторы разделения а для исследуемых пар сорбатов на адсорбенте Хезасорб-AW-HMDS $(\mathrm{Cam})_{4} \mathrm{Pz}-\mathrm{Pd}$ при $140{ }^{\circ} \mathrm{C}$

\begin{tabular}{|c|c|}
\hline Сорбаты $\left(\mathbf{t}_{\text {кип }},{ }^{\circ} \mathrm{C}\right)$ & $\alpha$ \\
\hline 3,4-лутидин $(179,1)$ - 3,5-лутидин $(172,2)$ & 1,51 \\
\hline 2,3-лутидин $(162,2)$ - 2,5-лутидин $(157,0)$ & 1,14 \\
\hline 4-пиколин $(145,4)-3$-пиколин $(144,0)$ & 1,04 \\
\hline 3 -пиколин $(144,0)$ - 2,6-лутидин $(144,0)$ & 1,62 \\
\hline этанол $(78,5)$ - бензол $(80,1)$ & 2,77 \\
\hline$n$-ксилол $(138,3)-M$-ксилол $(139,1)$ & 1,01 \\
\hline 3 -пиколин $(144,0)-n$-ксилол $(138,3)$ & 1,15 \\
\hline 3 -пиколин $(144,0)-м$-ксилол $(139,1)$ & 1,16 \\
\hline 2,6-лутидин $(144,0)-м$-ксилол $(139,1)$ & 1,87 \\
\hline 2,6-лутидин $(144,0)-n$-ксилол $(138,3)$ & 1,87 \\
\hline бензол $(80,1)$ - циклогексан $(81,7)$ & 2,52 \\
\hline пропанол-2 $(82,3)$ - циклогексан $(81,7)$ & 6,74 \\
\hline этанол $(78,5)$ - циклогексан $(81,7)$ & 7,00 \\
\hline
\end{tabular}

Межмолекулярные взаимодействия и в частности способность к комплексообразованию оказывают существенное влияние на селективность исследуемых неподвижных фаз, для оценки которой рассчитывали отношения приведенных времен удерживания $\alpha$.

Как было показано при анализе характеристик удерживания, межмолекулярные взаимодействия адсорбат - адсорбент сильно зависят от геометрии молекулы адсорбата. Данный факт, а также высокие значения $\alpha$ делает возможным использование сорбента «Хезасорб-AW-HMDS - (Cam) ${ }_{4} \mathbf{P z}-$ $\mathbf{P d}$ » для разделения отличающихся по геометрии

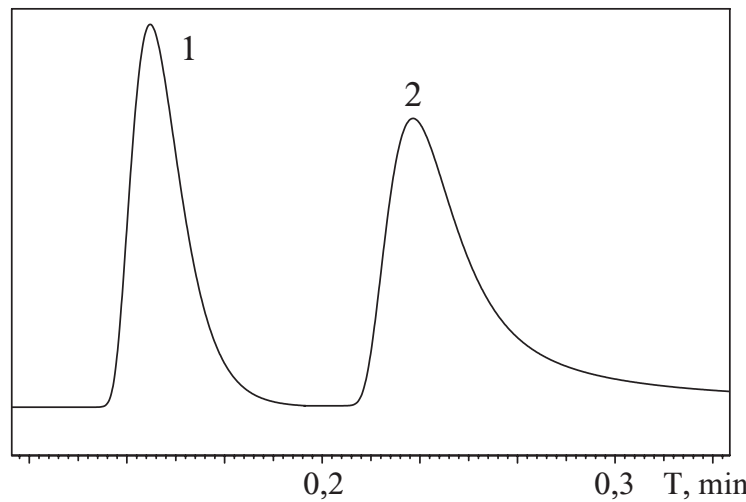

Рис. 2. Хроматограмма смеси циклогексана (1) и этанола (2), полученная при $140{ }^{\circ} \mathrm{C}$ на колонке «Хезасорб-AW-HMDS - (Cam) $)_{4}$ Pz-Pd»

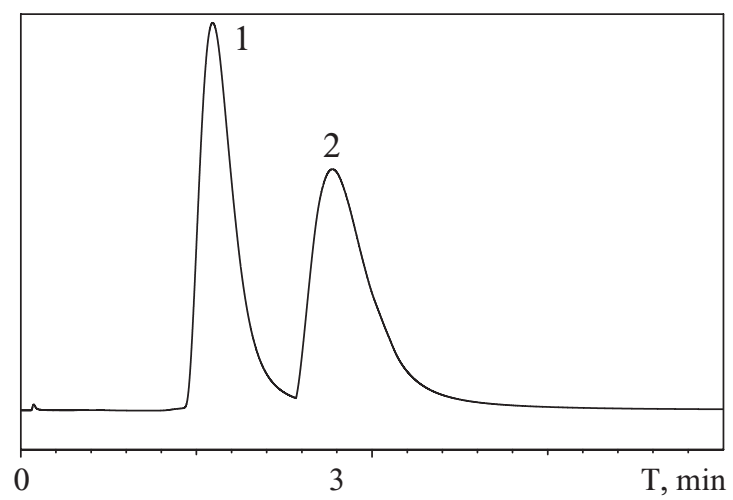

Рис. 3. Хроматограммы смеси 3,4-лутидина (1) и 3,5-лутидина (2), полученная при $140{ }^{\circ} \mathrm{C}$ на колонке «Хезасорб-AW-HMDS - (Cam) ${ }_{4}$ Pz-Pd»

молекул, особенно молекул структурных изомеров. Так, на данном сорбенте легко разделяются 3,4/3,5-лутидины $(\alpha=1,51)$. При использовании сорбентов на основе супрамолекулярных жидких кристаллов и мезоморфных комплексов меди и никеля значения факторов разделения для 3,4/3,5-лутидинов не превышают 1,40 [30-32].

Высокую способность к разделению данная стационарная фаза проявляет по отношению к сорбатам разной природы, но с близкой температурой кипения. Пара бензол/циклогексан на данном сорбенте имеет фактор разделения 2,52, пропанол-2/ циклогексан - 6,74, а этанол/циклогексан - 7,00. Данные показатели существенно превышают аналогичные для Хезасорб-AW-HMDS - (Cam) ${ }_{4} \mathbf{P z}-\mathbf{N i}$ [27] и Хроматон N-AW - (Cam) ${ }_{4} \mathbf{P z}-\mathbf{C u}$ [26].

Высокие значения фактора разделения как для структурных изомеров, так и для соединений разных классов показывают значительную универсальность данной стационарной фазы. 
Следует отметить, что макрогетероциклические 5,10,15,20-тетракис[3',5' -ди-(2',-метилбутилокси) фенил]-порфин $\mathrm{Ni}(\mathrm{II})$ [33] и тетра(4-mpem-бутил5-нитро)фталоцианин $\mathrm{Ni}(\mathrm{II})$ [34] имеют факторы разделения 3,4/3,5-лутидинов 1,43 и 1,27 соответственно, что существенно ниже значений $\alpha$ на исследуемых диатомитовых адсорбентах, модифицированных камфоразамещенным тетрапиразинопорфиразином (Cam) ${ }_{4} \mathbf{P z}-\mathbf{P d}$.

\section{Заключение}

Выполнена модификация поверхности диатомитового адсорбента Хезасорб-AW-HMDS тетра(1',7',7'-триметилбицикло[2.2.1]гептано-[2',3'b]-пиразино)-порфиразином $\mathrm{Pd}$.

Установлено, что данный металлокомплекс термоустойчив при высоких температурах, а также растворим во многих органических растворителях и низколетуч, что делает его удобным модификатором для адсорбентов-носителей.

Изучена сорбция ряда органических соединений из газовой фазы сорбентом на основе камфоразамещенного тетрапиразинопорфиразина (Cam) ${ }_{4} \mathbf{P z}$-Pd. Определены и сопоставлены характеристики удерживания изомеров диметилпиридина, метилпиридина, ксилола, спиртов и других углеводородов. Экспериментально показано, что вследствие физической модификации поверхность адсорбентов становится специфической, геометрически и химически более однородной.

В целом показано, что стационарная фаза на основе Хезасорба-AW-HMDS - (Cam) ${ }_{4} \mathbf{P z}-\mathbf{P d}$ является высокопроизводительной и эффективной, а также проявляет высокую селективность как по структурным изомерам, так и по соединениям разной природы, но с близкой температурой кипения.

\section{Лumepamypa}

1. Adahchour M., Beens J., Brinkman U.A.Th. J. Chromatogr. A. 2008. V. 1186. №1-2. P. 67-108. DOI 10.1016/j.chroma.2008.01.002.

2. Mottaleb M.A., Usenco S., O’Donnell J.G., Ramirez A.J., Brooks B.W., Chambliss C.K. J. Chromatogr. A. 2009. V. 1216. №5. P. 815-823. DOI 10.1016/j.chroma.2008.11.072.

3. Ghasemi E., Sillanpää M., Najafi N.M. J. Chromatogr. A. 2011. V. 1218. №3. P. 380-386. DOI 10.1016/j.chroma.2010.12.005.

4. Reis M.G., dos Reis M.M., Leath S., Stelwagen K. J. Chromatogr. A. 2011. V. 1218. №2. P. 316.

5. Pizarro C., Rodriguez-Tecedor S., Pěrez-del-Notario N., Gozalez-Saiz J.M. J. Chromatogr. A. 2011. V. 1218. №3. P. 518 .
6. Kaur N., Cabral J.-L., Morin A., Waldron K.C. J. Chromatogr. A. 2011. V. 1218. №2. P. 324-333.

7. Neng R.N., Mestre A.S., Carvalho A.P., J.M.F. Nogueira J.M.F. J. Chromatogr. A. 2011. V. 1218. №37. P. 62636270.

8. Noche G.G., Laespada M.E.F., Pavǒn J.L.P., Cordero B.M., Lorenzo S.M. J. Chromatogr. A. 2011. V. 1218. №37. P. 6240-6247.

9. Kopytin K.A., Bykov E.S., Onuchak L.A., Kudryashov S.Yu., Kuvshynova S.A., Burmistrov V.A. Russ. J. Phys. Chem. A. 2015. V. 89. №4. P. 688-672.

10. Buszewski B., Bocian S., Matyska M., Pesek J. J. Chromatogr. A. 2011. V. 1218. P. 441.

11. Bocian S., Vajda P., Felinger A., Buszewski B. Anal. Chem. 2009. V. 81. P. 6334.

12. Hrsg. E. Leibnitz, H.G. Struppe. Handbuch der GasChromatograpfie, Leipzig, Akad. Verl.-Ges. Geest \& Portig K.-G. 1984.

13. Kuvshinova S.A., Burmistrov V.A., Fokin D.S., Blokhina S.V., Koifman O.I. J. Analyt. Chem. 2009. V. 64. №5. P. 505-508. DOI 10.1134/S1061934809050128.

14. Onuchak L.A., Ukolova D.A., Burmatnova T.S., Kuraeva Yu.G., Kuvshinova S.A., Burmistrov V.A., Stepanova R.F. Russ. J. Phys. Chem A. 2015. V. 89. №1. P. 129135. DOI 10.1134/S0036024415010185.

15. Tugareva D.A., Kuraeva Yu.G., Onuchak L.A., Kapralova T.S., Kuvshinova S.A., Burmistrov V.A. Zhidk. krist. ikh prakt. ispol'z = Liq. Cryst. and their Appl. 2016. V. 16. №2. P. 52-61. (in Russian). DOI 10.18083/ LCAppl.2016.2.52.

16. Kuvshinova S.A., Fokin D.S., Litov K.M., Burmistrov V.A., Koifman O.I. Russ. J. Phys. Chem. A. 2010. V. 84. №11. P. 1956-1961. DOI: 10.1134/ S0036024410110233.

17. Kuvshinova S.A., Litov K.M., Kuvshinov G.V., Novikov I.V., Aleksandriiskii V.V., Burmistrov V.A., Koifman O.I. Russ. J. Gen. Chem. 2016. V. 86. №7. P. 1633-1640. DOI 10.1134/S1070363216070173.

18. Kuvshinova S.A., Burmistrov V.A., Novikov I.V., Alexandriysky V.V., Koifman O.I. Int. J. Recent Sci. Res. 2016. V. 7. №5. P. 11448-11458. http://recentscientific.com/ sites/default/files/5457.pdf.

19. Kuvshinova S.A., Burmistrov V.A., Novikov I.V., Alexandriysky V.V., Koifman O.I. J. Chromatogr. Sep. Tech. 2016. V. 7. № 1. P. 314-322. DOI 10.4172/21577064.1000314.

20. Burmistrov V.A., Kuvshinova S.A., Fokin D.S., Koifman O.I.. The VI China-Russia-Korea International Symposium about Advances on Chemical Engineering and New Materials Science. Daejeon, Korea, October 14-18, 2009. P. 71-76.

21. Jang C.K., Kim S.H., Jaung J.Y. J. Porphyrins Phthalocyanines. 2010. V. 14. P. 531-539.

22. Lee B.H., Jaung J.Y. Dyes and Pigments. 2003. V. 59. P. 135-142.

23. Vidal-Madjar C., Guiochon G. J. Chromatogr. Sci. 1971. V. 9. № 11. P. 664-672.

24. Procházka M., Smolková-Keulemansová E. J. Chromatogr. A. 1980. V. 189. P. 25-31. 
25. Кувшинов Г.В., Койфман О.И. Журнал физической химии. 2018. Т. 92. №10. С. 1612-1618.

26. Кувшинов Г.В., Койфман О.И. Российский химический журнал. 2017. T. LXI. №1. C. 48-55.

27. Кувиинов Г.В., Койфман О.И. Российский химический журнал. 2017. T. LXI. №4. C. 85-96.

28. Jang C.K., Byun S.H., Kim S.H., Lee D.K., Jaung J.Y. J. Porphyrins Phthalocyanines. 2009. V. 13. P. 794-797.

29. Вигдергауз М.C. Расчеты в газовой хроматографии. М.: Химия. 1978. 248 с.

30. Kuvshinova S.A., Burmistrov V.A., Fokin D.S., Blokhina S.V., Koifman O.I. Russ. J. Anal. Chem. 2009. V. 64. №5. P. 505-508.
31. Фокин Д.С., Кувиинова С.А., Бурмистров В.А., Блохина С.В., Койфман О.И. Жидк. крист. и их практич. использ. 2009. № 1(27). С. 71-77.

32. Крестов А.Г., Блохина С.В., Галяметдинов Ю.Г., Ольхович М.В., Лоханов В.В. Журн. физ. хим. 1993. T. 67. C. 151-154.

33. Кувшинов Г.В., Литов К.М., Кувиинова С.А., Бурмистров B.A. Siberian Youth Conference «Current Topics in Organic Chemistry», March 21-27, 2015, Sheregesh. P. 154.

34. Кувшинов Г.В., Майзлиш В.Е., Кувшинова С.А., Бурмистров В.А., Койфман О.И. Макрогетероциклы. 2016. T. 3. №9. C. 244-249. 